University of New Hampshire

University of New Hampshire Scholars' Repository

Physics Scholarship

Physics

$11-1-1991$

\title{
DMSP F7 observations of a substorm field-aligned current
}

\author{
R. E. Lopez
}

Harlan E. Spence

Boston University, harlan.spence@unh.edu

C. Meng

Follow this and additional works at: https://scholars.unh.edu/physics_facpub

Part of the Physics Commons

\section{Recommended Citation}

Lopez, R. E., H. E. Spence, and C.-I. Meng (1991), DMSP F7 observations of a substorm field-aligned current, J. Geophys. Res., 96(A11), 19409-19415, doi:10.1029/91JA01984.

This Article is brought to you for free and open access by the Physics at University of New Hampshire Scholars' Repository. It has been accepted for inclusion in Physics Scholarship by an authorized administrator of University of New Hampshire Scholars' Repository. For more information, please contact Scholarly.Communication@unh.edu. 


\title{
DMSP F7 Observations of a Substorm Field-Aligned Current
}

\author{
R. E. LOPEZ ${ }^{1}$ \\ Applied Research Corporation, Landover, Maryland
}

H. E. SPENCE

Space Sciences Laboratory, The Aerospace Corporation, Los Angeles, California

C.-I. MENG

The Johns Hopkins University Applied Physics Laboratory, Laurel, Maryland

\begin{abstract}
In this paper we present observations of a substorm field-aligned current (FAC) system that DMSP F7 traversed just after 0300 UT on April 25, 1985. Ground magnetometer data show that a major substorm was in progress at that time and that DMSP F7 flew through a region of predominantly upward FAC. The DMSP F7 magnetic field data are consistent with this interpretation. The precipitating particle data suggest that there were three distinct large-scale FAC systems. In ascending latitude these were a downward current, an upward current, and a paired upward/downward current system. We identify the first current, which was coincident with the diffuse aurora, as region 2. The next (upward) FAC was coincident with a spatially unstructured region of energetic $(-12 \mathrm{keV})$ electron precipitation. This was the substorm-associated FAC that made up part of the current wedge. The upward/downward current pair was coincident with a region of highly structured precipitation. We suggest that these currents may have been the duskside region 1 and, poleward of that, the extension of the dawnside region 1. The particle data show that the upward substorm current lay well equatorward of the boundary between open and closed field lines. In fact, using a model field, the equatorward boundary of the substorm FAC maps to the neutral sheet at $6.9 R_{E}$. While one should be cautious in stressing results obtained by mapping model field lines, our result is consistent with scenarios for substorms which postulate a disruption and diversion of the near-Earth cross-tail current.
\end{abstract}

\section{INTRODUCTION}

At substorm onset there is a reconfiguration of the magnetotail magnetic field toward a more dipolar orientation [McPherron et al., 1973]. This reconfiguration is due to the reduction of a portion of the cross-tail current [Lui, 1978; Kaufmann, 1987]. The change in the cross-tail current has been interpreted in terms of the formation of a substorm current wedge [e.g., McPherron et al., 1973] which diverts a portion of the current into the ionosphere via fieldaligned currents (FACs), thereby reducing the equatorial current within a longitudinally limited sector. The current wedge closes in the ionosphere via the westward traveling surge (WTS) [Lithr and Buchert, 1988]. The WTS is composed of a western region of intense net upward FAC and a more diffuse region of net downward FAC to the east [Inhester et al., 1981; Baumjohann et al., 1981]. Upward FAC also flows from the Harang discontinuity [e.g., Kunkel et al., 1986], which extends east of the WTS. This upward FAC is fed by the divergence of both eastward and westward electrojets. However, the bulk of the westward leg of the substorm current wedge corresponds to the upward current from the WTS.

The origin of the FACs which feed the substom current wedge, and thus the WTS, is an important question which bears on the basic nature of substorms. The boundary layer model [e.g., Rostoker and Eastman, 1987] explicitly addresses this issue. That

\footnotetext{
${ }^{1}$ Also at The Johns Hopkins University Applied Physics Laboratory, Laurel, Maryland.
}

Copyright 1991 by the American Geophysical Union.

Paper number $91 \mathrm{JA01984.}$

0148-0227/91/91JA-01984\$05.00 model postulates that the WTS is composed of upward FACs associated with the Harang discontinuity flowing through the plasma sheet boundary layer (PSBL) and mapping to the distant tail. On the other hand, other models, such as the near-Earth neutral line model [e.g., McPherron et al., 1973] and the current disruption model [e.g., Akasofu, 1972], suggest that the FACs which constitute the current wedge (and thus the WTS) have a relatively nearEarth origin. In this paper we will examine a case in which DMSP F7 flew through a FAC system during a substorm. Precipitating particle and magnetic field data from DMSP F7 and ground magnetometer data are available for this event. We will identify the substorm FAC portion of the current system and show that it was located well equatorward of the boundary between open and closed field lines. Moreover, we have mapped the equatorward boundary of the substorm FAC into the magnetotail using the Tsyganenko [1987] model, and we find that the boundary corresponds to $6.9 R_{E}$. This result is consistent with the idea that the region of substorm initiation lies relatively close to the Earth [e.g., Akasofu, 1972; Lopez and Lui, 1990] and that an essential feature of substorms is the disruption and diversion of the near-Earth current sheet.

\section{OBSERVATIONS}

We begin by presenting an overview of the observations. The event in question occurred during the early hours of April 25, 1985, and Figure 1 presents $A E$ for that day. The previous day there had been an extended quiet period of several hours which began at 1900 UT. At 0111 UT a small substorm occurred; that event has been studied in detail by Lopez et al. [1990]. A much larger substorm began just after 0200 UT. Figure 2 presents magnetogram data from Great Whale River (GWR; 67.4 ${ }^{\circ}, 356.6^{\circ}$ ). All ground station positions are given in PACE (Polar Anglo-American Conjugate Experiment) geomagnetic coordinates, described by Baker and Wing [1989]; the magnetograms were digitized with a 


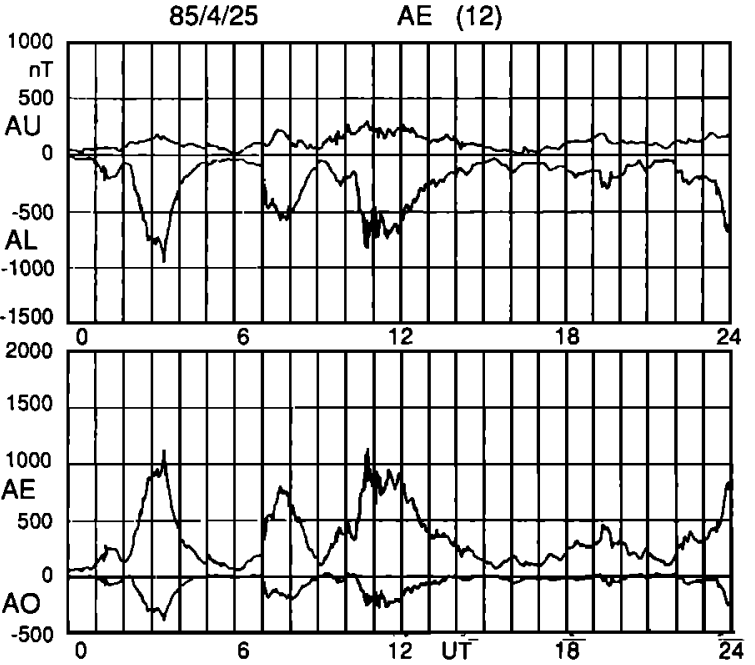

Fig. 1. $A E$ for April 25, 1985. A period of strong substorm activity began just after 0200 UT.

1-min resolution. Given the extremely quiet magnetosphere prior to the active period [Lopez et al., 1990], we may consider the values of the magnetic field at $0000 \mathrm{UT}$ in Figure 2 to represent the background levels for those components. Significant substom activity was recorded at GWR beginning after 0200 UT, and there were several distinct onsets, as evidenced by the repeated sudden $H$ and $Z$ variations and the positive $D$ spikes. Churchill recorded similar variations (not shown), which indicates that the region affected by the substorm extended at least 2 hours to the west of GWR. The continuously negative $Z$ component recorded after 0230 UT indicates that the center of the westward electrojet remained poleward of GWR. Just before 0300 UT (when GWR was at 2202 MLT) a sharp negative $Z$, accompanied by a positive $D$ perturbation, was observed. We associate these perturbations with one of the distinct onsets. Figure 3 presents mid-latitude magnetograms from Furstenfeldbruck (FUR; 42.54 ${ }^{\circ}, 87.45^{\circ}$ ) and Argentine Island (AI; $-50.35^{\circ}, 8.07^{\circ}$ ). We wish to focus on the interval beginning 0245 UT, when both stations observed large positive $H$ perturbations, a traditional indicator of substorm activity [e.g., Kokubun and McPherron, 1981]. In addition to the positive bays, both stations also recorded negative $D$ perturbations. It is important

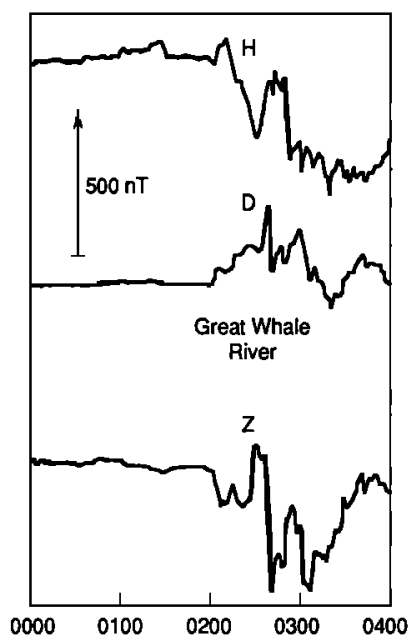

Fig. 2. Ground magnetometer data from Great Whale River.

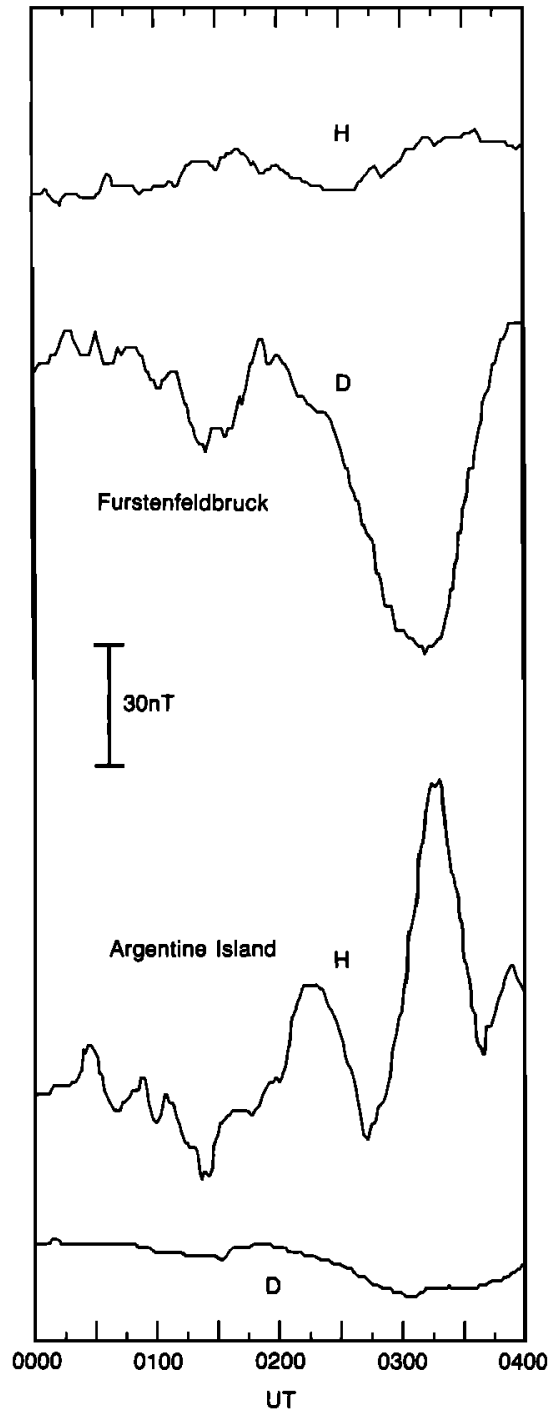

Fig. 3. Magnetograms from Furstenfeldbruck and Argentine Island.

to note (for purposes of interpreting the $D$ perturbations) that the stations are in opposite hemispheres. One should also note that the $D$ perturbation at $A I$ was weak relative to the $H$ perturbation, and vice versa at FUR.

DMSP F7 is a Sun-synchronous polar-orbiting satellite with an altitude of about $840 \mathrm{~km}$, a period of $101.5 \mathrm{~min}$, and an orbital plane approximately along the 1035-2235 local time meridian. Particle data (electrons and ions from $30 \mathrm{eV}$ to $30 \mathrm{keV}$ ) and magnetic field data are available during the period of interest. $A$ more detailed description of the DMSP spacecraft and the instrumentation is given by Hardy et al. [1984] and Gussenhoven et al. [1985]. Observations made by DMSP F7 of particle precipitation as the satellite passed over the southern polar region are presented in Plate 1 in spectrogram format; both ions (bottom panel) and electrons (top panel) are plotted. The lowest-energy ions (electrons) are at the top (bottom) of the panel, so that the lowest-energy particles of both species are at the center of the plot. The magnetic coordinates in the figure are PACE coordinates.

The particle data show an empty polar cap, a sharp poleward edge on the nightside, and a narrow dayside cusp; these features are indicative of southward interdisplanetary magnetic field $B_{z}$ [Makita and Meng, 1984; Hardy et al., 1986; Newell and Meng, 


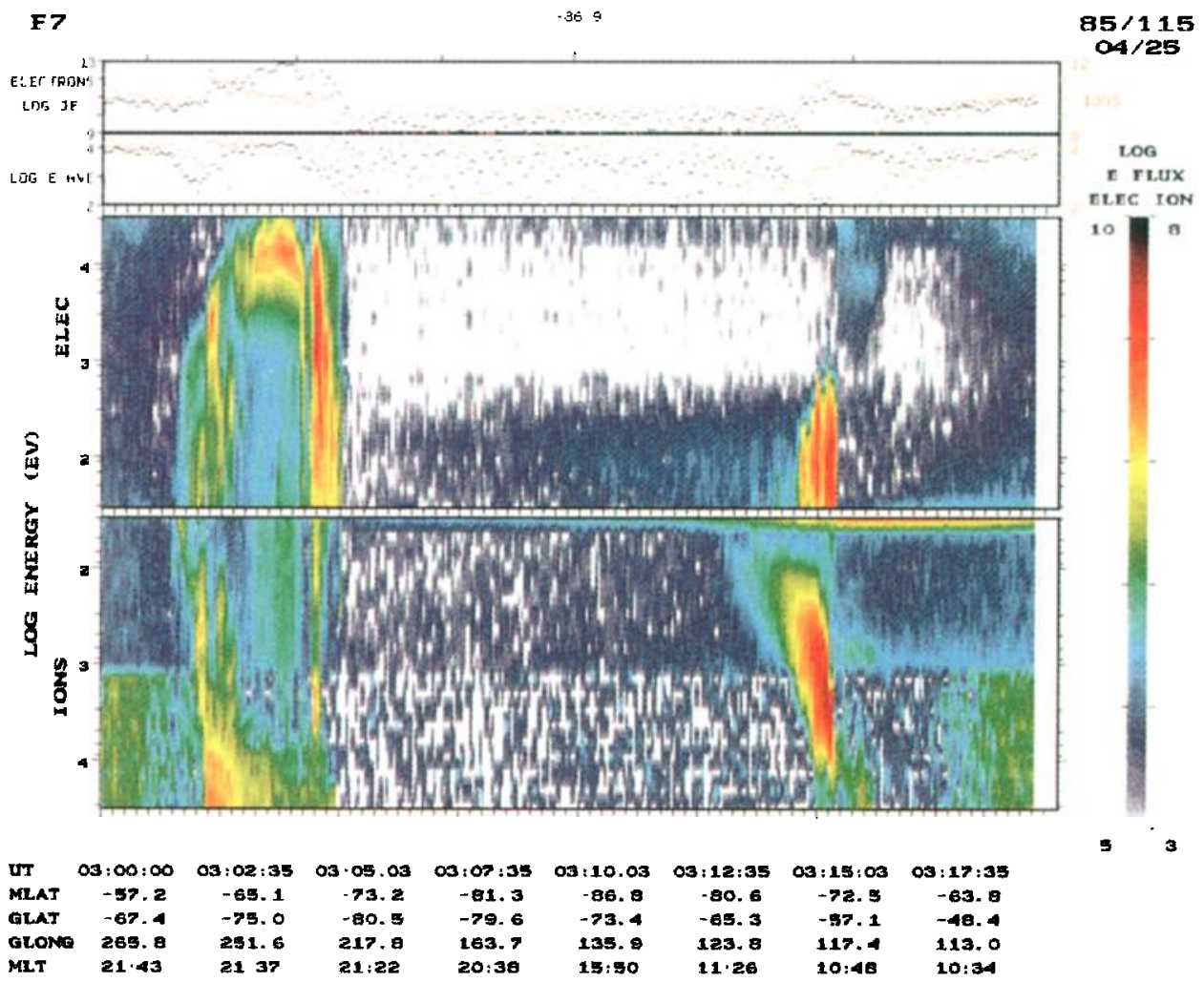

Plate 1. DMSP F7 ion and electron data during a polar cap pass on April 25, 1985. The data show a narrow cusp, an empty polar cap, and a sharp boundary between open and closed field lines.

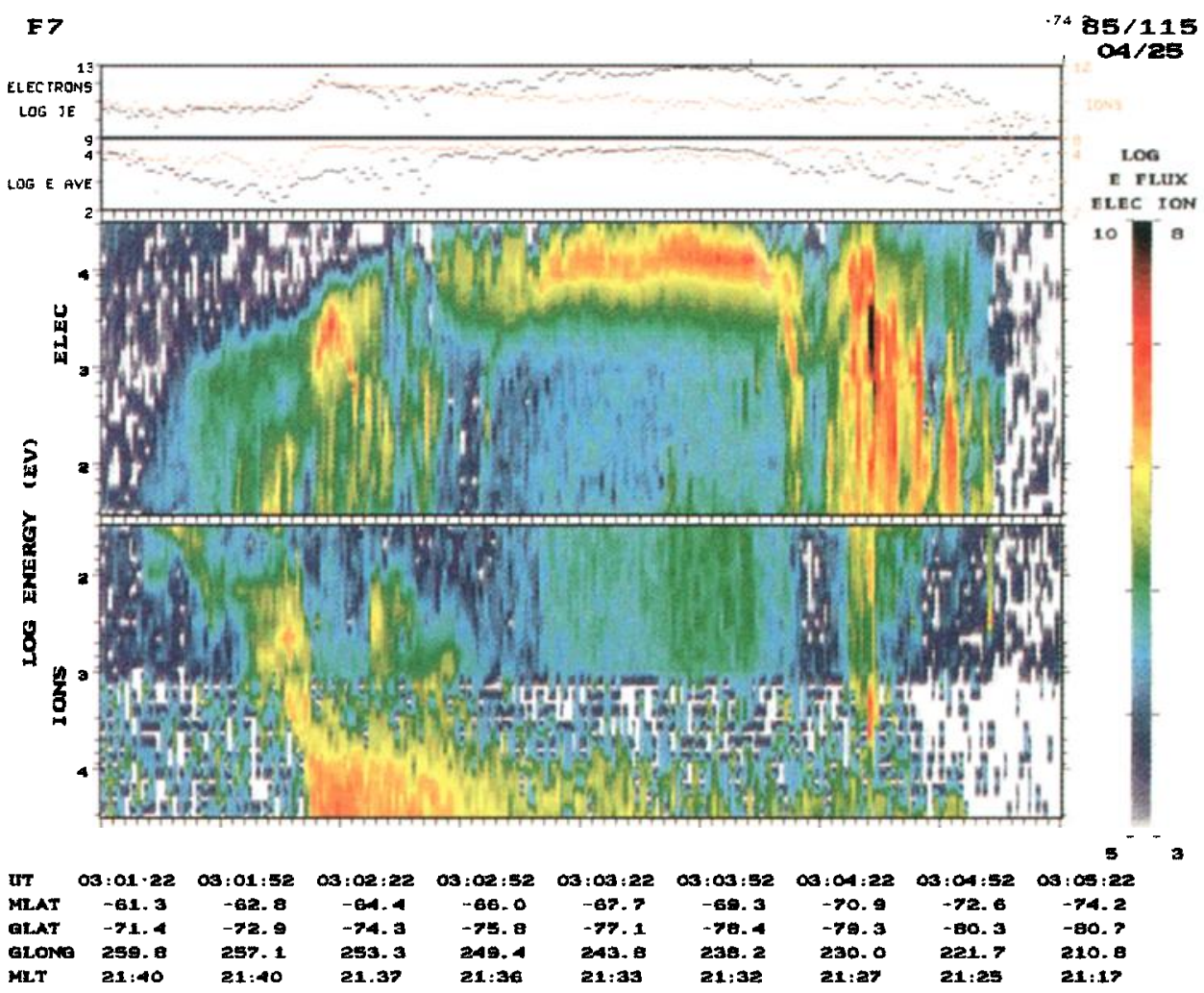

Plate 2. Four minutes of DMSP F7 particle data. The data show three distinct regions (from equatorward to poleward): (1) a region of diffuse precipitation (a small discrete arc was located within this region), (2) a broad, spatially unstructured region of energetic (12 keV) electron precipitation, and (3) a highly structured region whose poleward edge marks the boundary between open and closed field lines. 
1987]. We have confirmed this by examining IMP 8 magnetic field data (not shown); although those data are only available beginning 0240 UT, they do show that $B_{z}$ was southward with a magnitude of the order of $2.0 \mathrm{nT}$. The poleward boundary of the nightside precipitation marks the boundary between open and closed field lines. Plate 2 presents data from the same pass on the nightside, but at an expanded scale. At 0301:37 UT, DMSP F7 entered the diffuse aurora, which is characterized by spatially and spectrally unstructured precipitation [Feldstein and Galperin, 1985]. Imbedded within this region was a narrow discrete feature that the satellite encountered at 0302:12 UT. Following that, at -0303 UT, DMSP F7 entered a broad and spatially (though not spectrally) unstructured region of precipitating energetic ( $\sim 12 \mathrm{keV})$ electrons. Continuing poleward, there was a region of highly structured discrete precipitation that was quite different from the unstructured region both in spectral and spatial characteristics. Finally, the boundary between open and closed field lines (the poleward edge of the precipitation marking the boundary between plasma-filled and plasma-empty flux tubes) was encountered at $-73.2^{\circ}$ magnetic latitude (MLAT).

We would also like to mention two other points of interest relating to the particle data. First, the average energy of the ions shortly after 0302 UT increased as a function of geomagnetic latitude. This is in contrast to the statistical result of Hardy et al. [1989], which shows that the ion energy decreases with increasing latitude, and which was generally the case until just after 0302 UT. Thus the conditions observed were far from the statistical ones, suggesting that DMSP F7 detected freshly accelerated ions. Second, the DMSP F7 auroral image for this pass (not presented) shows that the region of intense electron precipitation coincided with bright aurorae. However, the highly disturbed nature of the aurorae in the image makes unambiguous identification of any specific surge feature problematic.

Figure 4 presents the magnetic field deflections measured by DMSP F7 in two formats: a polar plot (which is a south polar projection from inside the Earth) and a line plot. The polar plot shows only those components perpendicular to the radial vector. The line plot shows all three components of the field, where $\Delta B_{y}$ is the component parallel to the satellite trajectory, $\Delta B_{x}$ is the radial component, and $\Delta B_{z}$ is the cross-track component; this component points essentially westward. Also indicated on the figure is the location of the conjugate point for GWR at 0300 UT. The data show a clear net eastward deflection of the magnetic field vector during the passage through the auroral zone as DMSP F7 moved poleward (north to south). This is consistent with a passage by the satellite through a net upward FAC sheet. It is important to note that the data come from the southern hemisphere and that the polar plot presents the perspective of an observer looking from a northern position down to the Earth, so that in that plot an upward FAC (i.e., negative $\Delta B_{z}$ ) corresponds to a current going out of the back side of the figure.

The magnetic field deflection appears to have been composed of three major regions, each of which was coincident with a distinct precipitation region. The first region was marked by a slow westward deflection of the magnetic field which lasted until -0303 UT; this was coincident with diffuse auroral precipitation. Superimposed on this deflection, just after 0302 UT, there was a small bipolar structure, the poleward part of which was coincident with
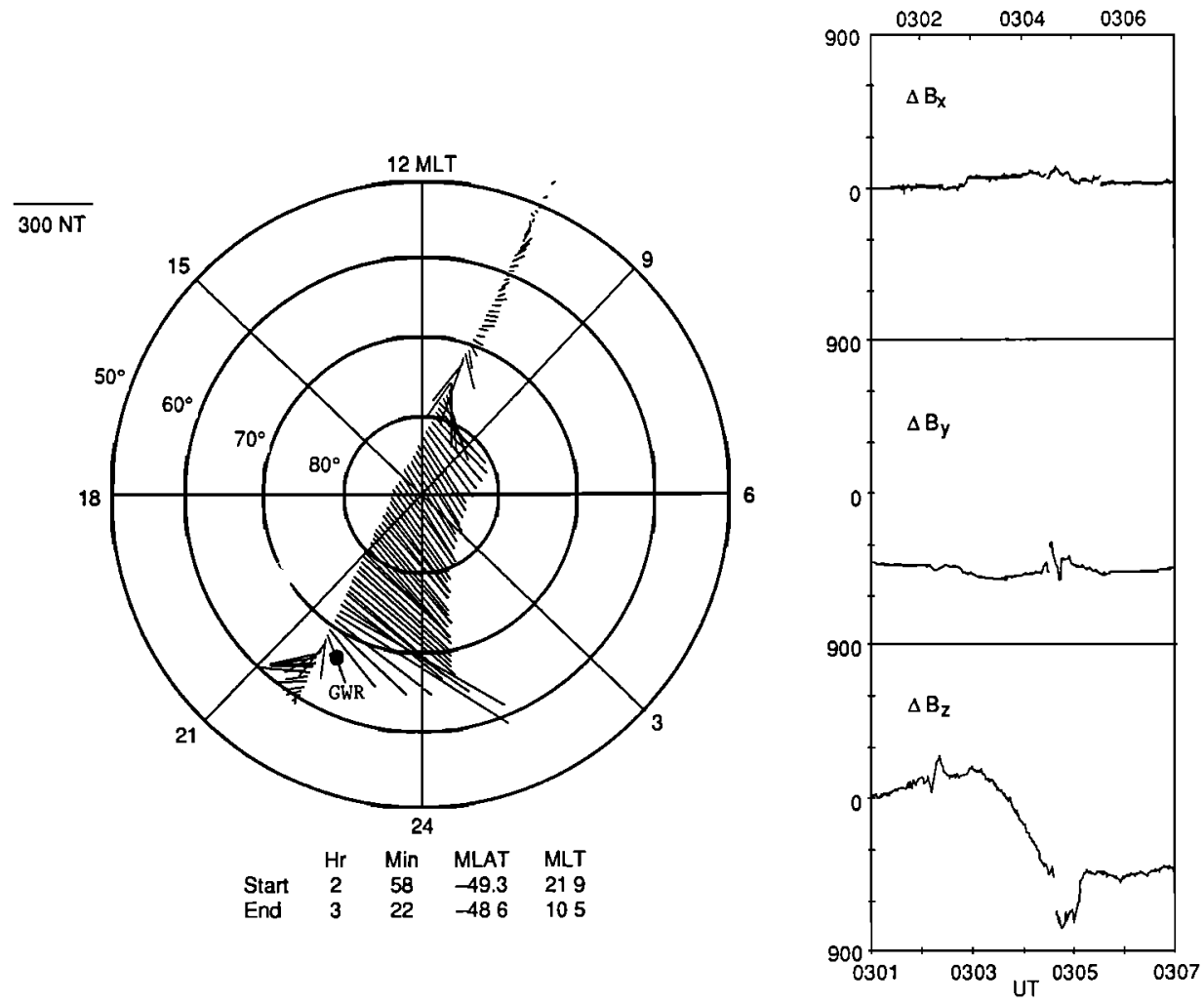

Fig. 4. Magnetometer data from DMSP F7 during a south polar pass. $\Delta B_{x}$ is the component parallel to the satellite trajectory, $\Delta B_{y}$ is radially inward, and $\Delta \Delta B_{z}$ is essentially westward. The data show a net eastward deflection of the magnetic field that we interpret as being due to a substorm-associated upward FAC. It is important to note that the polar plot is a south polar projection from inside the Earth, so an upward current in the polar plot corresponds to a current going out of the back of the figure. The conjugate point for GWR at 0300 UT is indicated by the dot. 
the discrete particle feature observed at that time. The second region was characterized by a large eastward deflection that began at 0302:56 UT. The smooth variation in $\Delta B_{2}$ in this region was coincident with the spatially uniform $12-\mathrm{keV}$ electron precipitation. This region ended at -0304:20 UT, at which time DMSP F7 exited the uniform precipitation region. After the small precipitation gap seen in Plate 2, the slope of the $\Delta B$ decrease changed significantly. A minimum $\Delta B_{z}$ value was soon reached, $\Delta B_{z}$ oscillated near that value and then increased to a value roughly equal to the $\Delta B_{z}$ level at 0304:20UT. This third region was coincident with the region of highly structured energetic electron precipitation. Also, it is important to note that the major part of the $\Delta B_{z}$ decrease was located poleward of the GWR conjugate point. Having presented an overview of the observations, we now proceed to examine their implications.

\section{DISCUSSION}

The $A E$ data show that during the period in question, considerable substorm activity occurred, and this is reflected in the magnetograms discussed above. The sign of the $D$ perturbation indicates whether a given mid-latitude station is east or west of the center of the substorm current wedge [e.g., Nagai, 1982]. Both Argentine Island and Furstenfeldbruck observed a negative $D$ deflection, and since Argentine Island is in the southern hemisphere, the current wedge was centered between those two stations. We have confirmed this by examining other mid-latitude magnetograms (not shown) from San Juan, Fredericksburg, and Tucson. All those stations, which are west of $\mathrm{AI}$, recorded positive $D$ perturbations in association with the positive bay, which is expected when a northern hemisphere station is west of the center of the current wedge. Similarly, the station at Toledo, located between $A I$ and FUR, recorded a negative $D$ deflection (not shown). Moreover, the relative sizes of the $D$ and $H$ perturbations lead us to conclude that AI was near to and just west of the center of the current wedge.

The substorm was composed of multiple onsets, and the midlatitude data show that an onset occurred at 0245 UT. It is that onset that we associate with the perturbations recorded at GWR from 0245 UT onward. This includes the $D$ spike at GWR that peaked at 0300 UT, which we interpret as being related to a surgelike feature, although we have no visual evidence that a surge moved over GWR at that time. The behavior of the $H$ component also suggests that the western edge of a WTS passed directly over GWR [e.g., Akasofu et al., 1966]. This implies that at 0300 UT, GWR was underneath a region of upward FAC [e.g., Samson and Rostoker, 1983], which is consistent with the mid-latitude observations.

The magnetic field observations made by DMSP F7 are consistent with southern hemisphere and heading poleward, an eastward deflection of the magnetic field can be interpreted as a net upward field-aligned current. As was pointed out above, the FAC system traversed by DMSP F7 appears to have been composed of three major regions. Assuming that the azimuthal deflections were caused by FACs, in increasing latitude those regions correspond to a downward FAC (with an upward/downward/upward structure imbedded within it), an upward FAC, and an upward/downward pair.

The most equatorward FAC was downward, and it was coincident with the diffuse aurora. We identify this current as region 2 because the sign and the latitudinal location of the current are consistent with region 2 and because region 2 has its origin in the near-Earth ring current [Iijima et al., 1990]. Within the region 2 current was a small, discrete, precipitation structure; associated with that structure was a bipolar magnetic perturbation. This suggests that discrete auroral ares can map to the very near-Earth region that is the source of region 2 .

The third current system was directed upward, and it was coincident with a broad region of unstructured precipitation; it was also responsible for most of the $\Delta B_{2}$ variation. We believe that this current was the substorm-associated FAC and that the region of precipitation corresponded to a portion of the WTS east of the westernmost edge but well within the region of intense upward FAC. This interpretation is consistent with the observations of GWR, which suggests that a surge moved over the station just minutes before DMSP F7 traversed the current system. The latitude of point conjugate to GWR would place that station within (but on the equatorward side of) the uniform precipitation region and the upward FAC, which is consistent with the negative $Z$ observed at GWR. Our interpretation is also consistent with the result of Craven and Frank [1987]. They found that the substorm auroral brightening often begins at near $66^{\circ}$ or $67^{\circ}$ (magnetic latitude) and then expands primarily poleward. Furthermore, the spectral structure of the precipitation is typical of WTS precipitation, although the latitudinal extent of the feature is larger than one might expect (D. Gorney, personal communication, 1990). Since the aurora was probably expanding poleward [e.g., Craven and Frank, 1987], it is possible that some of the latitudinal extent was temporal in origin, rather than spatial. Also, the previous expansions may have been responsible for generating some of the observed precipitation region. Moreover, the DMSP F7 image (not presented) shows that the satellite passed through bright aurorae, lending further support to our interpretation. However, given that it is not possible in this case to unambiguously identify a specific surge in the image, our identification of the 12-keV electron precipitation and its associated upward FAC with a portion of a WTS should be considered tentative.

Another possible interpretation is that DMSP F7 traversed the Harang discontinuity, which is generally believed to be a source of upward FAC [e.g., Kunkel et al., 1986]. The observations, however, suggest that this scenario is unlikely. The relatively large negative $Z$ perturbation relative to the small negative $H$ perturbation that occurred at 0300 UT suggests that GWR was located poleward of the center of the eastward electrojet and equatorward of the center of the westward electrojet. In that case, GWR was located very near the Harang discontinuity itself. Since GWR was in the northern hemisphere and DMSP F7 was in the southern hemisphere, one should ask "How well can we trust the conjugate point for GWR?" Wu et al. [1991] have recently addressed this issue, and they found that during the spring and fall, geomagnetic coordinate conjugacy holds rather well. We find additional support for that result in this case using the Tsyganenko [1987] model, which shows that the southern ionospheric footprint of the field line originating at GWR (at $110 \mathrm{~km}$ altitude) is located at $\left(-67.27^{\circ}\right.$, $357.62^{\circ}$ ). Thus the conjugate point for GWR (see Figure 4) suggests that the bulk of the upward FAC that we call the substorm FAC was located poleward of GWR. The bulk of that FAC would have been drawn from the substorm-enhanced westward electrojet. Only a small portion at the equatorward edge of the westward electrojet might have been related to the upward FAC at the Harang discontinuity. However, any association between the equatorward portion of the upward FAC and the Harang discontinuity does not affect the conclusion that the upward current was a portion of the westward leg of the substorm current wedge.

The final current system was composed of two FACs of roughly equal magnitude. These FACs were coincident with the region of structured precipitation poleward of the broad upward FAC. That 
region was quite different from the region equatorward of it, and it seems reascnable to suspect that these two currents were part of a system separate from the broad upward FAC. This is consistent with the fact that the currents were roughly of equal magnitude. Iijima and Potemra [1976] showed that the dawnside region 1 current (downward) extends into the premidnight sector poleward of the duskside region 1 current (upward). This corresponds to the observed pattern of currents in our case. Moreover, such quasi-permanent paired current sheets have been observed in the PSBL by Nagai et al. [1990], and they are relatively independent of the substorm-associated currents. Therefore it is reasonable to postulate that this poleward system of roughly equal and oppositely directed current sheets may correspond to the quasi-permanent region 1 currents. The overall structure of the particle precipitation regions and their associated FACs is illustrated in Figure 5.

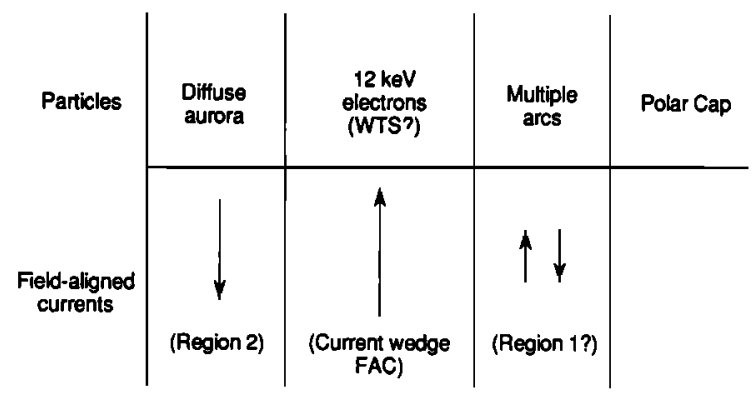

Fig. 5. Schematic illustration of the particle precipitation regions and their inferred field-aligned currents.

We may estimate the position of the source region in the magnetosphere of the substorm current using the magnetic field model of Tsyganenko [1987]. We find that the equatorward edge of the substorm FAC maps to a radial distance of $6.9 R_{E}$ and that the poleward edge of that FAC maps to $24.9 R_{E}$. Thus the near-Earth region would appear to have been the source of much of the substorm current that directly connects to the WTS. A similar conclusion was reached by Lopez et al. [1990], who examined multipoint observations of the small substorm which occurred just after 0100 UT. We would like to point out that results obtained using a model field, especially during a substorm period, can be of questionable reliability. However, the mapping of the equatorward edge of the FAC cannot be greatly in error since at those distances from the Earth the dipole component is quite strong. In fact, SCATHA data (not shown) indicate that the near-midnight magnetic field at $R=5.8 R_{E}$ was not extremely taillike at the time of the event.

Regardless of whether one believes the above mapping, it is important to note that both the substorm FAC and the upward region 1 FAC were located well equatorward of the boundary between open and closed field lines and that the main substom current in that local time sector was upward. In fact, the openclosed boundary was located $6^{\circ}$ poleward of the equatorward edge of the substom-associated upward FAC. Given that the ionospheric projection of the PSBL is $\leqslant 1^{\circ}$ [Dandouras et al., 1986], the current must have been flowing through and connected to the central plasma sheet. Thus the observations appear to be consistent with substorm models which require the disruption and diversion of the cross-tail current sheet in the near-Earth region [e.g., Akasofu, 1972; McPherron et al., 1973], and are inconsistent with substom models which locate the upward substom currents in the PSBL.

\section{CONCLUSION}

On April 25, 1985, DMSP F7 flew through a field-aligned current system in the auroral region. Ground magnetic field data show that the local time sector traversed by DMSP F7 was located in the western part of the current wedge and that the net FAC was upward. The FAC system was composed of three major current systems. The most equatorward current was downward; it corresponds to region 2, and it was colocated with the diffuse aurora. The next current was upward, coincident with a region of spatially unstructured energetic electron precipitation, and it corresponds to the FAC in the substorm current wedge. We have tentatively identified this precipitation region and its attendant upward FAC with a portion of a westward traveling surge. The two other currents were of roughly equal magnitude and coincident with a region of highly structured precipitation. These currents may correspond to the region 1 current system. All upward FACs were located well equatorward of the boundary between open and closed field lines. Moreover, using the Tsyganenko [1987] model, we estimate that the equatorward edge of the substorm current system mapped to the neutral sheet at $6.9 R_{E}$ and the poleward edge mapped to the neutral sheet at $24.9 R_{E}$. The observations and model mapping are consistent with scenarios which place the region of substorm initiation in the near-Earth magnetotail and inconsistent with scenarios which place the region of substorm initiation in the distant tail.

Acknowledgments. We are pleased to acknowledge the aid of P. Newell, whose generous assistance was, as is often the case, invaluable. The DMSP F7 magnetic field data were graciously provided by F. Rich and the Geophysics Laboratory; the plots were produced by J. James, whose help is much appreciated. The ground magnetograms were provided by the World Data Center. We would also like to thank T. Lui, D. Sibeck, D. Gorney, and T. Rosenberg for several helpful conversations. Finally, we would like to thank one of the referees for bringing to our attention the point concerning the latitudinal dependence of the average ion energy, and the other referee for helpful detailed comments. The work performed at APL was supported by NASA under Task 1 of contract NO0039-89-C-5301 and by NSF grant ATM-8713212. The work performed at The Aerospace Corporation was supported by the U.S. Air Force System Command's Space System Division under contract F04701-88-C-0089.

The Editor thanks J. S. Dandouras and another referee for their assistance in evaluating this paper.

\section{REFERENCES}

Akasofu, S.-I., Magnetospheric substorms: A model, in Solar Terrestrial Physics/1970, part II, edited by D. Dyer, Pp. 131-151, D. Reidel, Hingham, Mass., 1972.

Akasofu, S.-I., C.-I. Meng, and D. S. Kimball, Dynamics of the aurora, IV, Polar magnetic substorms and westward travelling surges, J. Amos. Terr. Phys., 28, 498-496, 1966.

Baker, K. B., and S. Wing, A new magnetic coordinate system for conjugate studies at high latitudes, J. Geophys. Res., 94, 9139-9143, 1989. Baumjohann, W., R. J. Pellinen, H. J. Opgenoorth, and E. Nielsen, Joint two-dimensional observations of ground magnetic and ionospheric electric fields associated with auroral zone currents: Current systems associated with local auroral breakups, Planet. Space Sci., 29, 431-447, 1981.

Craven, J. D., and L. A. Frank, Latitudinal motions of the aurora during substorms, J. Geophys. Res., 92, 4565-4573, 1987.

Dandouras, J., A. Saint-Marc, H. Reme, J. A. Sauvaud, and G. K. Parks, Particle dynamics of the plasma sheet boundary layer, Adv. Space Res.. 6, 159-163, 1986.

Feldstein, Y. I, and Yu. I. Galperin, The auroral luminosity structure in the high-latitude upper atmosphere: Its dynamics and relationship to the large-scale structure of the Earth's magnetosphere, Rev. Geophys., 23, 217-275, 1985.

Gussenhoven, M. S, D. A. Hardy, F. Rich, and W. J. Burke, High-level spacecraft charging in the low-altitude polar auroral environment, $J$. Geophys. Res., 90, 11,009-11,023, 1985.

Hardy, D. A, L. K. Schmitt, M. S. Gussenhoven, F. J. Marshall, H. C. Yeh, T. L. Shumaker, A. Hube, and J. Pantazis, Precipitating electron and ion 
detectors (SSJ/4) for the block 5D/flights 6-10 DMSP satellites: Calibration and data presentation, Rep. AFGL-TR-84-0317, Air Ponce Geophysics Laboratory, Hanscom Air Force Base, Mass., 1984.

Hardy, D. A., M. S. Gussenhoven, K. Riehl, R. Burkhardt, N. Heinemann, and T. Schumaker, The characteristics of polar cap precipitation and their dependence on the interplanetary magnetic field and the solar wind, in Solar Wind-Magnetosphere Coupling, edited by Y. Kamide and J. A. Slavin, pp. 575-604, Terra Scientific, Tokyo, 1986.

Hardy, D. A., M. S. Gussenhoven, and D. Brautigam, A statistical model of auroral ion precipitation, J. Geophys. Res., 94, 310-392, 1989.

lijima, T., and T. A. Potemra, The amplitude distribution of field-aligned currents at northern high latitudes observed by Triad, J. Geophys. Res., 81, 2165-2174, 1976.

Iijima, T., T. A. Potemra, and L. J. Zanetti, Large-scale characteristics of magnetospheric equatorial currents, J. Geophys. Res., 95, 991-999, 1990.

Inhester, B, W. Baumjohann, R. A. Greenwald, and E. Nielsen, Joint twodimensional observations of ground magnetic and ionospheric electric fields associated with auroral zone curnents, 3, Auroral zone currents during the passage of a westward travelling surge, J. Geophys., 49, 155-162, 1981.

Kaufmann, R. L., Substorm currents: Growth phase and onset, J. Geophys. Res.. 92, 7471-7489, 1987.

Kokubun, S., and R. L. McPherron, Substorm signatures at synchronous altitude, J. Geophys. Res., 86, 11,265-11,277, 1981.

Kunkel, T., W. Baumjohann, J. Untiedt, and R. A. Greenwald, Electric fields and currents at the Harang discontinuity: A case study, J. Geophys., 59, 73-86, 1986.

Lopez, R. E., and A. T. Y. Lui, A multisatellite case study of the expansion of a substorm current wedge in the near-Earth magnetotail, J. Geophys. Res., 95, 8009-8017, 1990.

Lopez, R. E., H. L hr, B. J. Anderson, and P. T. Newell, Multipoint observations of a small substorm, J. Geophys. Res., 95, 18,897-18,912, 1990.

Luhr, H., and S. Buchert, Observational evidence for a link between currents in the geotail and in the auroral ionosphere, Ann. Geophys., 6, 169-176, 1988.
Lui, A. T. Y., Estimates of current changes in the geomagnetic tail associated with a substorm, Geophys. Res. Lett., S, 853-856, 1978.

Makita, K., and C.-I. Meng, Average electron precipitation patterns and visual aurora characteristics during geomagnetic quiescence, $J$. Geophys. Res., 89, 2861-2872, 1984.

McPherron, R. L. C. T. Russell, and M. P. Aubry, Satellite studies of magnetospheric substorms on August 15, 1968; 9, Phenomenological model for substorms, J. Geophys. Res., 78, 3131-3149, 1973.

Nagai, T., Observed magnetic substorm signatures at synchronous altitude, J. Geophys. Res., 87, 4406-4417, 1982.

Nagai, T., K. Takahashi, T. A. Potemra, R. W. McEntire, R. E. Lopez, and D. M. Klumpar, The structure of the Birkeland current system in the post-midnight plasma sheet, Geophys. Res. Lett., 17, 1057-1060, 1990.

Newell, P. T., and C.-I. Meng, Cusp width and $B_{z}$ : Observations and aconceptual model, J. Geophys. Res., 92, 13,673-13,678, 1987.

Rostoker, G., and T. E. Eastman, A boundary layer model for magnetospheric substorms, J. Geophys. Res., 92, 12,187-12,201, 1987.

Samson, J. C., and G. Rostoker, Polarization characteristics of Pi2 pulsations and implications for their source mechanisms: Influence of the westward travelling surge, Planet. Space Sci., 31, 435-458, 1983.

Tsyganenko, N. A., Global quantitative models of the geomagnetic field in the cislunar magnetosphere for different disturbance levels, Planet. Space Sci., 35, 1347-1358, 1987.

Wu, Q., T. J. Rosenberg, L. J. Lanzerotti, C. G. Maclennan, and A. Wolfe, Seasonal and diurnal variations of the latitude of the westward auroral electrojet in the nightside polar cap, J. Geophys. Res., 96, 1409-1419, 1991.

R. E. Lopez and C.-L. Meng, The Johns Hopkins University Applied Physics Laboratory, Laurel, MD 20723.

H. Spence, Space Sciences Laboratory, The Aerospace Corporation, M2-260, P.O. Box 92957, Los Angeles, CA 90009.

(Received May 29, 1990;

revised April 8, 1991;

accepted July 25,1991 .) 